\title{
Trichoderma asperellum efficiently protects Quercus robur leaves against Erysiphe alphitoides
}

\author{
Tomasz Oszako (D) D Dmitry Voitka • Marcin Stocki • Natalia Stocka • \\ Justyna Anna Nowakowska (iD • Anna Linkiewicz (iD) - Tom Hsiang • Lassaâd Belbahri • \\ Daria Berezovska • Tadeusz Malewski (D)
}

Accepted: 15 November 2020 /Published online: 21November 2020

(C) The Author(s) 2020

\begin{abstract}
The protective effects of Trichoderma asperellum IZR D-11 as a biocontrol agent against the powdery mildew Erysiphe alphitoides infecting leaves of Quercus robur were evaluated for the first time. A strain of Trichoderma had earlier been isolated in Belarus, and was identified in this study as T. asperellum by sequencing of three genomic markers: internal transcribed spacer, translation elongation factor 1 alpha
\end{abstract}

T. Oszako

Department of Plant Protection, Forest Research Institute, 05-090 Sękocin Stary, Poland

e-mail: T.Oszako@ibles.waw.pl

D. Voitka

Institute of Plant Protection, 2 Mira Street, 223,011, Priluki, Belarus

e-mail:d.voitka@tut.by

\section{Stocki}

Faculty of Civil Engineering and Environmental Sciences, Institute of Forest Sciences, Białystok University of Technology, Wiejska 45E, 15-351, Białystok, Poland

e-mail: m.stocki@pb.edu.pl

N. Stocka

Faculty of Civil Engineering and Environmental Sciences, Białystok University of Technology, Wiejska 45E, 15-351, Białystok, Poland

e-mail: n.gierasimiuk@doktoranci.pb.edu.pl

\section{J. A. Nowakowska $(\bowtie) \cdot$ A. Linkiewicz}

Faculty of Biology and Environmental Sciences, Institute of Biological Sciences, Cardinal Stefan Wyszynski University in Warsaw, Wóycickiego 1/3 Street, 01-938, Warsaw, Poland e-mail: j.nowakowska@uksw.edu.pl and RNA polymerase II subunit 2, with over $99.2 \%$ identity to corresponding genomic sequences in GenBank. When applied once in the first year just after onset of powdery mildew disease, $T$ asperellum IZR D11 reduced disease progression and continued to reduce powdery mildew levels during the following three years. Photosynthetic activity as represented by chlorophyll fluorescence measured in oak seedlings was increased

\author{
A. Linkiewicz \\ e-mail: a.linkiewicz@uksw.edu.pl \\ T. Hsiang \\ Environmental Sciences, University of Guelph, Guelph, ON N1G \\ 2 W1, Canada \\ e-mail: thsiang@uoguelph.ca \\ L. Belbahri \\ Laboratory of Soil Biology, University of Neuchatel, Neuchatel, \\ Switzerland \\ e-mail: lassaad.belbahri@unine.ch \\ D. Berezovska \\ Department of Biochemistry and Pharmacogenomics, Faculty of \\ Pharmacy, Medical University of Warsaw, Banacha 1 Street, 02- \\ 097, Warsaw, Poland \\ e-mail: dariadasha.berezovska@gmail.com
}

\section{T. Malewski}

Department of Molecular and Biometric Techniques, Museum and Institute of Zoology, Polish Academy of Science, Wilcza 64

Street, 00-679 Warsaw, Poland

e-mail: tmalewski@miiz.waw.pl 
in treated plants, and greater assimilate production was also found. The use of this antagonistic fungus increased the total water content in oak leaves suggesting that T. asperellum IZR D-11 can serve as a preventive measure to reduce energy losses in the process of water transpiration. GC-MS analysis detected 49 volatile compounds in the headspace of pure cultures of T. asperellum. Sesquiterpenes represented mainly by daucene, dauca-4(11),8-diene and isodaucene were the largest group of compounds emitted. We speculate that these volatiles from $T$. asperellum IZR D-11 may be involved in induced resistance in the plant, but further research is needed. The above results suggest that T. asperellum strain IZR D-11 has potential as a biocontrol agent of oak powdery mildew in forest nurseries.

Keywords Powdery mildew · Biocontrol .

Trichoderma $\cdot$ Oak $\cdot$ Volatile organic compounds

\section{Introduction}

Common oak Quercus robur L. and sessile oak Q. petraea (Matt.) Liebl. are major oaks species in central and eastern European forests. Oak stands occupy about $6 \%$ of the total forest area of Poland. Since the early 1900's, records of powdery mildews affecting European oaks have been mentioned since they are important fungal diseases (Mougou et al. 2008). In Europe, powdery mildew infections of common oak are caused by Erysiphe alphitoides (Braun and Cook 2012) (syn. Microsphaera alphitoides Griffon \& Maubl.), which is the most prevalent and damaging foliar fungal species in oak stands, and along with primary insect attacks, they cause periodic dips in oak health (Topalidou and Shaw 2016). Common oak is one of the most susceptible species to E. alphitoides (Desprez-Loustau et al. 2011), and this pathogen is often mentioned as an inciting factor in European oak decline (Keča et al. 2016). Powdery mildew has particularly damaging effects on young seedlings, in nurseries, plantations, and can even damage mature trees under conditions favorable to disease (Marçais and DesprezLoustau 2014).

Fungi from the genus Trichoderma are commonly found in all climatic zones. The most typical habitats of these fungi include soil and rotting wood (Druzhinina et al. 2006). Trichoderma spp. have been reported to exhibit antagonistic effects against at least 29 species of pathogenic fungi representing 18 genera such as Armillaria, Chondrostereum, Phytophthora, Rhizoctonia, Sclerotinia, and Verticillium (Druzhinina et al. 2011; Contreras-Cornejo et al. 2016). Species of Trichoderma have long been recognized as biological control agents (BCA) of plant diseases (ContrerasCornejo et al. 2011; Hermosa et al. 2012; Zhang et al. 2016). Isolate T-39 of $T$. harzianum was the first commercialized fungal BCA (Trichodex $®$ ) for plant diseases (Tronsmo and Dennis 1977). Trichoderma sp. IZR D-11 is the basis of Fungilex L (Belarus, State Registration № 06-0078 dating from 28 November 2013) which is used for reduction of Botrytis cinerea on cucumber, parsley, dill, lettuce, but the species name is not known.

The mode of action of Trichoderma spp. as biocontrol agents can be direct by parasitizing the target organisms, or indirect through competition, modifications of the environment, or promoting plant defense mechanisms (Benitez et al. 2004). Trichoderma harzianum T39 applied to roots of greenhouse cucumber was able to reduce powdery mildew (caused by Sphaerotheca fusca) by 75-90\% (Elad et al. 1998), and this was attributed to induced resistance. Elad (2000) considered that induced resistance was the main mode of action of T. harzianum against powdery mildew fungi. Another species, T. asperellum, has been used as a biocontrol agent to control Pythium myriotylum, which causes root rot in cocoyam (Mbarga et al. 2012), and Sclerotium sclerotiorum, which causes stem rot in carnation (Vinodkumar et al. 2017). Trichoderma asperellum reduced conidial germination of Leveillula taurica, causing powdery mildew on pepper (López et al. 2019).

Volatile organic compounds (VOCs) produced by plant growth-promoting fungi such as species of Phoma, Cladosporium or Ampelomyces significantly reduced fungal and bacterial disease severity in Arabidopsis by eliciting induced resistance against pathogens (Naznin et al. 2014). Volatiles have been acknowledged for their role in promoting plant growth and disease resistance against pathogens (Thissera et al. 2020; Cheffi et al. 2019; Ben et al. 2018; Belbahri et al. 2017; Mefteh et al. 2017). Trichoderma spp. are also known to have plant-growth promoting activities (Benitez et al. 2004), and volatiles produced by Trichoderma spp. are also known to induce resistance against plant pathogens (Lee et al. 2016). Gas Chromatography-Mass Spectrometry (GC-MS) analysis of VOCs and Liquid Chromatography High Resolution 
Mass Spectrometry (LC-HRMS) analysis of secondary metabolites have been effective in the discovery of numerous molecules with plant growth promoting abilities such as auxin derivatives and compounds able to interfere with pathogen growth such as antibiotics.

The main goal of this study was to identify the Trichoderma species to which Trichoderma IZR D-11 belongs, and to evaluate its protective effect against a powdery mildew disease of common oak (Q. robur) and to investigate the production of secondary metabolites that may affect the interaction between our isolate and the host $Q$. robur. The assessment of health of oak seedlings was based on visual disease symptoms and monitoring of physiological changes (chlorophyll fluorescence and water index).

\section{Material and methods}

\section{Source of isolates}

Trichoderma sp. IZR F 183 D-11 (called here Trichoderma IZR D-11) was obtained from the Institute of Plant Protection, Minsk, Belarus and is available from the Belarusian Collection of Non-pathogenic Microorganisms as Trichoderma sp. БИМ F-457Д. Тo observe morphological features, the isolate was grown on several media e.g. wort-agar (Merck KGaA, Germany), PDB (HiMedia Laboratories Pvt. Limited, India), Sabouraud agar (Sigma-Aldrich, Milwaukee, WI, USA), and Czapek medium (DifcoTM, MD USA). Colony color and shape and fruiting structures were assessed after 5 days of fungus incubation at $25^{\circ} \mathrm{C}$ in the dark. Cultivation of Trichoderma IZR D-11 for inoculation was done in liquid media on PDB at $25^{\circ} \mathrm{C}$ and $200 \mathrm{rpm}$ (PSU-20i, e-biogenet, Poland). The microscopic characters of mycelia were investigated on a Nikon Eclipse H550L microscope, using the Imaging Software package NIS-Elements F 2.30, SP3 (Build 374) (Nikon).

Every year, powdery mildew develops on mature Q. robur trees in the Seckocin forest $\left[52^{\circ} 6^{\prime} 21^{\prime \prime} \mathrm{N}\right.$, $\left.20^{\circ} 51^{\prime} 47^{\prime \prime} \mathrm{E}\right]$ near Warsaw, Poland. In 2016, leaves from oak trees with powdery mildew were used as the source of natural inoculum of the powdery mildew fungus in the first year. In subsequent years, infected seedlings which were also in the greenhouse, provided the source of inoculum. Oak seedlings were infected by E. alphitoides via direct contact and dispersal of ascospores via air in the greenhouse. Infected leaves were attached to healthy ones with rubber band and in addition infected potted seedlings were mixed with healthy ones.

Molecular identification of fungal isolates

Trichoderma IZR D-11 was grown in liquid culture for $72 \mathrm{~h}$, and spores and hyphae were collected. Oak leaves bearing white patches of Erysiphe sp. were collected for species identification. Spores of the powdery mildew were collected by scraping off white powdery material from few heavily infected common oak leaves collected in July 2016.

Genomic DNA for both organisms was extracted using a NucleoSpin Plant II Kit (Macherey-Nagel, Düren, Germany), following the manufacturer's instructions. For each sample, DNA was eluted in $50 \mu \mathrm{H}_{2} \mathrm{O}$, and extracted DNA was stored at $-20{ }^{\circ} \mathrm{C}$. For identification of Trichoderma IZR D-11, three markers were used, i.e. internal transcribed spacer region (ITS), translation elongation factor 1 alpha (Tef-1a) and RNA polymerase II subunit 2 (Rpb2). The internal transcribed spacer ITS amplification was done as described by Hermosa et al. (2000) using forward ITS1 (5'- TCCGTAGGTGAACCTGCGG-3') and reverse ITS4 (5'- TCCTCCGCTTATTGATATGC-3') primers (White et al. 1990). Translation elongation factor 1 alpha (Tef-1a) amplification was done as described by Carbone and Kohn (1999) using forward EF1-728F (5'CATCGAGAAGTTCGAGAAGG-3') and reverse TEF1LLErev (5'-AACTTGCAGGCAATGTGG-3') primers. RNA polymerase II subunit 2 (Rpb2) amplification was done as described by Liu et al. (1999) using forward fRPB2-5f (5'-GAYGAYMGWGATCAYTTYGG-3') and reverse fRPB2-7cr (5'-CCCATRGCTTGYTTRCCCAT$\left.3^{\prime}\right)$ primers. PCR primers were synthesized by SigmaAldrich (Milwaukee, WI, USA). For identification of the powdery mildew, the ITS1 and ITS4 primers were used with PCR conditions described by White et al. (1990).

PCR reactions were performed in $20 \mu \mathrm{l}$ volumes each containing $1 \mu \mathrm{M}$ each primer pair (forward and reverse), $10 \mu 12 x$ RedTaq Ready Mix (SigmaAldrich, Milwaukee, WI, USA) and $2 \mu$ of genomic DNA as template. Cycling was performed using a Veriti 96-Well Thermal Cycler (ThermoFisher Scientific, Waltham, MA, USA) as follows: an initial denaturation step of $95^{\circ} \mathrm{C}$ for $3 \mathrm{~min}$, followed by 35 cycles of $94^{\circ} \mathrm{C}$ for $30 \mathrm{~s}, 55^{\circ} \mathrm{C}$ for $30 \mathrm{~s}$, and $72^{\circ} \mathrm{C}$ for $30 \mathrm{~s}$, and a final extension step. 
All PCR products were visualized by UV illuminator after running through $1 \%$ agarose gel and staining with ethidium bromide (Sigma-Aldrich, Milwaukee, WI, USA). Excess dNTPs and unincorporated primers were removed from the PCR product using the Clean-Up Purification Kit (A\&A Biotechnology, Gdynia, Poland). Finally, DNA was eluted in $40 \mu \mathrm{H}_{2} \mathrm{O}$ and the obtained amplicons were sequenced with an ABI 3500xL genetic analyser (ThermoFisher Scientific, Waltham, MA, USA) following the manufacturer's procedure. For species identification, a criterion of $99 \%$ identity over a minimum of 500 base pairs was applied. The assignment of sequences obtained during this study to species was performed by the BOLD Identification System (Ratnasingham and Hebert 2007) and BLAST (Altschul et al. 1990).

Plant material and treatment conditions

In spring 2015, 62 acorns of $Q$. robur collected from the Sękocin forest were planted singly in pots in a $2: 1$ mixture of horticulture soil ( $\mathrm{pH} 5.5$ ) and vermiculite, and placed outdoors close to adult oaks showing powdery mildew infections. In spring 2016, 42 healthy oneyear-old potted oak seedlings were chosen for the experiment with Trichoderma and 20 were left as control seedlings and placed separately in the greenhouse. Diseased leaves from mature oaks infected by powdery mildew were collected in 2016 and rubbed onto leaves of all 42 seedlings to propagate the fungus, prior to their placement in the greenhouse for further growth and infection of leaves.

On 27 July 2016, when the first symptoms of powdery mildew developed on seedling leaves, one group of 21 was sprayed weekly for three weeks with a spore suspension in MiliQ water $\left(1 \times 10^{7}\right.$ spores $\left./ \mathrm{ml}\right)$ of Trichoderma IZR D-11. The other set of 21 seedlings not treated with Trichoderma were randomly interspersed among the treated plants. All 42 seedlings were kept in the greenhouse for the next three years to monitor long term effects of Trichoderma IZR D-11 application on seedlings exposed to powdery mildew.

Rating scale for powdery mildew infection

Powdery mildew was assessed once a year in midSeptember on the 42 seedlings using a five-point damage rating scale (Khvasko 2004) as follows:
0 healthy leaves (symptomless);

1 little disease (mycelium coverage of $25 \%$ of leaves surface);

2 medium disease (mycelium coverage from 26\% to $50 \%$ of leaves surface);

3 strong disease (mycelium coverage from $51 \%$ to $75 \%$ of the leaves surface);

4 severe disease (mycelium coverage more than $76 \%$ of the leaves surface).

The formula for calculation of biological efficacy (BE) of Trichoderma IZR D-11 reflecting disease suppression was as follows:

BE $(\%)=100-(100 \times$ disease incidence of treatment/disease incidence of control) (Shin et al. 2017).

In order to evaluate if disease levels differed significantly before and after Trichoderma treatment, an analysis of variance (one-way ANOVA at $P=0.05$ ) was conducted as well as the nonparametric Kruskal-Wallis test of significance between treatments during the three consecutive weeks using STATISTICA 12 (SoftStat, Warszawa, Polska).

Detection of Trichoderma in oak leaves and rhizosphere soil by qPCR

In mid-July 2017, a year after inoculation with Trichoderma IZR D-11, ten oak leaves from 10 seedlings with no symptoms of powdery mildew disease were randomly collected from 21 treated plants to check for the presence of Trichoderma by quantitative PCR. In consecutive years 2018 and 2019, leaves from 10 seedlings and soil from 10 pots were randomly sampled, to be tested for presence of $T$. asperellum, which had been identified from the sequencing results. From each leaf, about $100 \mathrm{mg}$ of tissue was used for DNA extraction. In parallel, rhizosphere soil from 10 pots $(0.5 \mathrm{~g}$ per pot $)$ was also subjected to DNA extraction. Genomic DNA from leaves was extracted using a NucleoSpin Plant II Kit, and gDNA from soil with the NucleoSpin Soil Kit (Macherey-Nagel, Düren, Germany), following manufacturer's instructions. Primers specific for ITS sequences of $Q$. robur (AH005165.2) and the T. asperellum (MT133310.1) were designed using Primer-BLAST (Ye et al. 2012).

Briefly, qPCR reactions were performed in $20 \mu \mathrm{l}$ volumes each containing $1 \mu \mathrm{M}$ of each primer (forward and reverse), $10 \mu \mathrm{l} 2 \mathrm{x}$ FastStart SYBR Green Master 
Mix (Sigma-Aldrich, Milwaukee, WI, USA) and $2 \mu \mathrm{l}$ of genomic DNA as template. Thermocycling conditions consisted of initial denaturation at $95{ }^{\circ} \mathrm{C}$ for $3 \mathrm{~min}$, followed by 40 cycles at $95{ }^{\circ} \mathrm{C}$ for $30 \mathrm{~s}, 55^{\circ} \mathrm{C}$ for $30 \mathrm{~s}$ and $72{ }^{\circ} \mathrm{C}$ for $30 \mathrm{~s}$. Amplifications were performed using a RotorGene 6000 (Qiagen, Hilden, Germany) following manufacturer's instructions. Ct values below 35 were considered a positive detection response. The negative controls (no DNA) produced no amplification products over 40 cycles.

Analysis of VOCs emitted by Trichoderma asperellum IZR D-11

Volatile secondary metabolites of the identified strain IZR D-11 as Trichoderma asperellum were analyzed with headspace solid phase microextraction and gas chromatography-mass spectrometry (HS-SPME/GCMS) methods. The research was performed using previously developed methodology (Stocki et al. 2018, 2019; Isidorov et al. 2019; Oszako et al. 2019). Petri dishes with Trichoderma asperellum IZR D-11 were sealed with parafilm and warmed for $30 \mathrm{~min}$ at $40{ }^{\circ} \mathrm{C}$. Afterwards, the parafilm was pierced by a needle protecting the SPME fiber (Supelco, Bellefonte, PA, USA) and the DVB/CAR/PDMS (divinylbenzene/carboxen/polydimethylsiloxane) fiber was exposed to the headspace gas phase. After $30 \mathrm{~min}$ of exposure, the SMPE fiber was placed for $10 \mathrm{~min}$ in an injection port of the $\mathrm{GC}-$ MS apparatus for thermal desorption of volatile substances from fiber. The GC-MS analyses were done on an Agilent 7890A gas chromatograph with an Agilent 5975C mass spectrometer (Agilent Technologies Inc., CA, USA). The chromatographic separation was performed using a capillary column HP-5MS (30 m $\times$ $0.25 \mathrm{~mm} \times 0.25 \mu \mathrm{m})$ at a helium flow rate of $1 \mathrm{ml} /$ min. The injector worked in a splitless mode at $250{ }^{\circ} \mathrm{C}$, with initial column temperature at $35^{\circ} \mathrm{C}$, rising to $250{ }^{\circ} \mathrm{C}$ at $5{ }^{\circ} \mathrm{C} / \mathrm{min}$. The ion source and quadrupole temperatures were $230{ }^{\circ} \mathrm{C}$ and $150{ }^{\circ} \mathrm{C}$, respectively. Electron ionization mass spectra were obtained at an ionization energy $70 \mathrm{eV}$. The detection was performed in a full scan mode from 29 to 600 a.m.u. After integration, the content of each component in the total ion current (\% TIC) was calculated. Mass spectral data and calculated retention indices were used to identify components. Mass spectrometric identification was carried out with an automatic system of GC-MS data processing supplied by NIST and Wiley mass spectra libraries. Retention indices of compounds were determined taking into account $\mathrm{C} 5-\mathrm{C} 40 n$-alkanes retention times. To confirm reliable identification of compounds, experimental retention indices $\left(\mathrm{RI}_{\text {exp }}\right.$.) were compared with literature values of retention indices $\left(\mathrm{RI}_{\text {lit. }}\right)$.

Chlorophyll fluorescence and water content in leaves

In August 2016, chlorophyll fluorescence was measured directly on oak leaves with a Handy PEA (Handy Plant Efficiency Analyser) fluorometer from Hansatech Instruments Ltd. (King's Lynn, Nortfolk, Great Britain). These measurements of physiological stress of investigated oaks were done on the central part of each leaf blade in an area of $4 \mathrm{~mm}^{2}$. In total, 10 measurements were made on randomly chosen leaves for each treated and untreated plant. Prior to measurements, seedlings were kept for 45-60 min in the dark at room temperature. The measurements were made following manufacturer instructions, with a $3500 \mu \mathrm{mol} \mathrm{m} \mathrm{s}^{-2} 1$ light pulse for $1 \mathrm{~s}$. Several photosynthesis parameters were assessed, namely initial fluorescence $\left(\mathrm{F}_{\mathrm{o}}\right)$, maximal fluorescence $\left(F_{M}\right), F_{v}=F_{M}-F_{o}$, Tfm - maximum time value of fluorescence (Fm), and total Performance Index PI. The mean data were tested by LSD (0.05).

Water content was calculated for a middle leaf from each plant including Trichoderma-treated plants as nontreated controls following Mazets et al. (2012). The water content in the leaves was calculated as follows:

$\mathrm{L}=100 \times\left[\left(\mathrm{M}_{\mathrm{f}}-\mathrm{M}_{\mathrm{d}}\right) / \mathrm{M}_{\mathrm{d}}\right]$,

where : $\mathrm{L}-$ mean of leaf moisture (\%),

$M_{\mathrm{f}}$ is the fresh mass, and $M_{\mathrm{d}}$ is the dry mass.

\section{Results}

Cultural and morphological features of Trichoderma asperellum IZR D-11

When the diameter of the colony grown on wort-agar reached $90 \mathrm{~mm}$, its macromorphological and microscopic characters were examined. The colonies were circular, edges were smooth, and the colony profiles were convex. The aerial mycelium was white in the initial period of growth, but became green with sporulation. The base substrate mycelium was white. The color of the reverse side of the colony was light yellow. 
Colony zone lines were noticeable in the form of concentric rings. On PDB, the colonies were similar with regular round shape and clearly defined colony margins. The profile was also convex, and the texture was tomentose. The color of the colony was yellow-green, with the reverse side light yellow (Fig. S1). The center was craterlike, with concentric rings toward the margins. On the Sabouraud medium, colonies had the regular round shape with clearly defined margins. The profile was convex and the texture was woolly. The color of the colony was yellow-green, with a light yellow reverse side. The center was not noticeably different. On the Czapek medium colonies had regular round shape, the colony margins were irregular with diffuse hyphae. The profile was convex with a velvety texture. The color of the colony was intense green, with base light yellow on reverse side. The center was crater-like with concentric zone lines toward the margins. On all media, conidiophores were produced. The conidiophores were branched with bottle-shaped phialides, located with whorls $2-3$ or singly, and $6.4 \times 1.4 \mu \mathrm{m}$. Sporulation was abundant and collected in spherical heads. Conidia were ellipsoid, $3.1 \times 2.6 \mu \mathrm{m}$, and greenish in mass. Chlamydospores were unicellular, terminal, and roughly spherical, measuring $20.5 \times 21.2 \mu \mathrm{m}$ (Fig. S2) These measurements were based on 100 observations.

Identification of fungal isolates

PCR amplifications of Trichoderma IZR D-11 strain DNA yielded the following amplicon sizes for each genomic region: $603 \mathrm{bp}$ for ITS, $500 \mathrm{bp}$ for Tef-1a, and 1069 bp for Rpb2. The BOLD Identification System placed the queried ITS sequence as Trichoderma asperellum with $99.17 \%$ identity. With BLAST, 93 records were found with $100 \%$ identity: 79 belonged to T. asperellum, 6 to Trichoderma sp., 3 to T. asperelloides, 2 to T. viridae, 2 to T. yunnanense and 1 to $T$. koningiosis. With BLAST, among 10 records of Rpb2 with $100 \%$ identity to the IZR D-11 sequence, three belonged to $T$. asperellum, three to T. asperelloides and four to Trichoderma sp. From eight records of Tef-1a (with $99 \%$ identity to the IZR D-11 sequence) three belonged to T. asperellum and five to Trichoderma sp. Based on these results, we concluded that IZR D-11 belongs to Trichoderma asperellum. The obtained sequences were deposited in GenBank and were assigned by the following accession numbers: MT133310.1, MT197117.1 and MT197116.1 for ITS, Tef-1 $a$ and Rpb2, respectively.

Sequencing of the powdery mildew ITS-amplicon resulted in a $622 \mathrm{bp}$ fragment which matched Erysiphe alphitoides (MK357383.1) at 99\% identity over the entire length. The obtained sequence has been deposited in GenBank (accession number KY346982).

Disease suppression with Trichoderma asperellum IZR D-11

Seedlings treated with T. asperellum IZR D-11 on 27 July 2017 , showed smaller powdery mildew severity $(0$ - healthy, 4 - highly diseased) compared to the untreated controls (Fig. 1).
Fig. 1 Condition of common oak leaves in August 2016 which had been treated with Trichoderma asperellum IZR-D11 in July 2016 (a), in comparison to the untreated control (b).

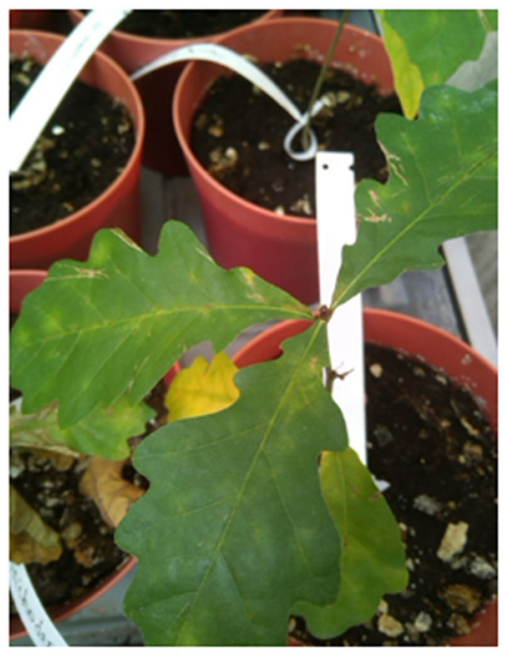

a

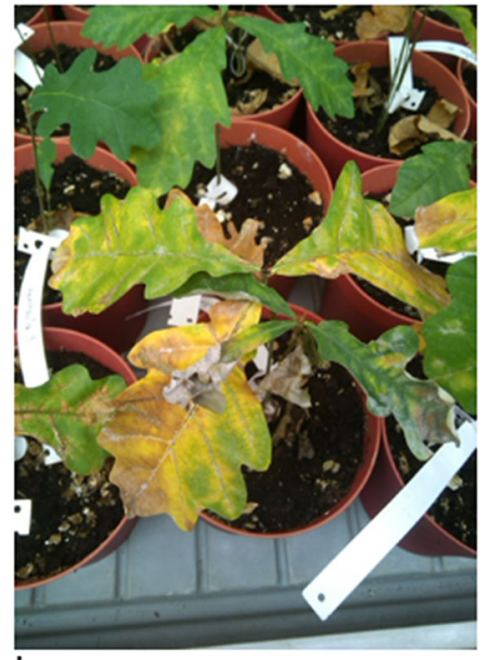

$\mathrm{b}$ 
Table 1 Effect of T. asperellum IZR D-11 treatment on oak powdery mildew caused by E. alphitoides with disease ratings of $0=$ healthy and $4=$ highly diseased.

\begin{tabular}{lllll}
\hline Treatment & \multicolumn{2}{l}{ Powdery mildew disease rating [mean value \pm S.E] } & \\
\cline { 2 - 5 } & $\begin{array}{l}\text { before } \\
\text { treatment }\end{array}$ & $\begin{array}{l}7 \text { days after the first } \\
\text { treatment }\end{array}$ & $\begin{array}{l}7 \text { days after the second } \\
\text { treatment }\end{array}$ & $\begin{array}{l}7 \text { days after the third } \\
\text { treatment }\end{array}$ \\
\hline $\begin{array}{l}\text { Untreated control } \\
\begin{array}{l}\text { Trichoderma } \\
\text { asperellum }\end{array}\end{array}$ & $0.62 \pm 0.29 \mathrm{a}$ & $1.48 \pm 0.32 \mathrm{~b}$ & $2.43 \pm 0.47 \mathrm{~d}$ & $2.81 \pm 0.35 \mathrm{e}$ \\
\hline
\end{tabular}

Values marked with the same letter do not differ significantly $(\mathrm{p}<0.05)$.

On a scale of $0=$ healthy to $4=$ diseased, the first rating before biocontrol application in in 2016 gave disease rating values of 0.57 for the treatment set of plants compared to 0.62 for the control plants which were not significantly different (Table 1). A week later after the first $T$. asperellum IZR D-11 treatment with continued powdery mildew development, the difference became more apparent and was statistically significant with disease rating at 1.00 for treated plants and 1.48 for untreated plants. After the third treatment, the difference was statistically significant with 2.10 for the treated plants and 2.81 for untreated control plants (Table 1). Based on ANOVA, the group of treated plants significantly differ from the control $(p=0.032)$, independently of the treatment conditions (days).

The $T$. asperellum IZR D-11 treatment significantly reduced levels of powdery mildew on the leaves of oak seedlings for the subsequent three years in the greenhouse, where they were maintained and monitored annually (Table 2).

Table 2 Residual and biological efficacy of Trichoderma asperellum IZR D-11 inoculated three times in the first year on the development of oak powdery mildew E. alphitoides in the subsequent three years where disease was rated as $0=$ healthy and 4 = highly diseased.

\begin{tabular}{llll}
\hline Year & Treatment & $\begin{array}{l}\text { Powdery Mildew } \\
\text { Disease Rating }\end{array}$ & $\begin{array}{l}\text { Biological } \\
\text { Efficiency [\%] }\end{array}$ \\
\hline 2017 Control & 3.22 & - \\
& $\begin{array}{l}\text { T. asperellum } \\
\text { IZR D-11 }\end{array}$ & 0.21 & 93.4 \\
2018 Control & 2.98 & - \\
& $\begin{array}{l}\text { T. asperellum. } \\
\text { IZR D-11 }\end{array}$ & 0.52 & 82.5 \\
2019 & $\begin{array}{l}\text { Control } \\
\text { T. asperellum } \\
\text { IZR D-11 }\end{array}$ & 3.61 & - \\
& 0.77 & 78.6 \\
\hline
\end{tabular}

Detection of Trichoderma asperellum in oak leaves and rhizosphere soil by qPCR

Primers specific to $Q$. robur (AH005165.2) ITS were designed by Primer-BLAST: the forward primer, 5'ACCTGCACAGCGGAACG-3', has a Tm of $60.3^{\circ} \mathrm{C}$, and the reverse primer, $5^{\prime}-$ AATTCATTAGACGC CGACCG -3 , has a Tm of $58.4{ }^{\circ} \mathrm{C}$. The predicted amplicon size was $191 \mathrm{bp}$. The same way were designed primers specific to $T$. asperellum (MT133310.1) ITS: 5'-CCTGCGGAGGGATC ATTACC-3', has a Tm of $60.0^{\circ} \mathrm{C}$, and the reverse primer, 5'-AAGAAATACGTCCGCGAGGG-3', has a Tm of $55.0^{\circ} \mathrm{C}$. The predicted amplicon size was $169 \mathrm{bp}$. Accuracy of designed primers were tested on DNA extracted from a $T$. asperellum IZR D-11 culture and $Q$. robur seedlings.

The overall qPCRs analysis performed with the ITS primers specific for T. asperellum and Q. robur yielded positive results with DNA for $T$. asperellum (Ct 23.18-25.26) and Q. robur (Ct 20.04-23.12) while primers specific $T$. asperellum not yielded any positive signal for DNA of $Q$. robur. Similarly, primers designed for $Q$. robur not yielded any signal with DNA of $T$. asperellum (Table S1). None of leaves tested gave positive result of Trichoderma $(\mathrm{Ct}>40)$, however the fungus was present in all sampled rhizosphere soil of treated oaks (Ct 26.8333.08). To exclude possibility that DNA extracted from leaves contains inhibitors, the qPCR analysis was performed with primers specific for $Q$. robur. qPCR and this yielded positive results for all analyzed samples (Ct 20.04-24.12). This indicated that extracted DNA was free of inhibitors and that the lack of signals with primers specific for T. asperellum was associated with lack of $T$. asperellum DNA in analyzed samples. 
Volatile secondary metabolites of Trichoderma asperellum

To better understand the mechanism of biocontrol activity, the secondary metabolites produced by the fungus were assessed. A chromatogram with HS-SPME/GC-MS analysis of VOCs emitted by $T$. asperellum is presented in the Fig. 2 . The volatiles emitted by $T$. asperellum contained 49 compounds (Table S2). Chemical analysis revealed VOC's including ones unique to T. asperellum (Table S2). Sesquiterpenes were the largest group of volatiles emitted by T. asperellum, and their content (\% of TIC) reached nearly $80 \%$. Daucane type sesquiterpenes e.g. daucene, dauca4(11),8-diene and isodaucene dominated among them.

The composition of $T$. asperellum VOCs was also rich in aliphatic alcohols, especially 3-hepten-1-ol. Aliphatic carbonyls such as acetone, 3-octanone and acetoin were found, as well as esters, including ethyl tiglate, ethyl 3-hydroxybutanoate and methyl 2ethylhexanoate. T. asperellum also emitted phenylethyl alcohol, linalool and 1,2-dimethylsulfide (Table S2).
Fluorometric analysis of oak leaves and water content

Fluorometric analysis in oak seedling leaves treated with T. asperellum IZR-D1 showed that the total performance index of chlorophyll fluorescence (PI) was higher (nearly double) than in the control (Table S3). Total performance index showed statistically significant difference $(p<0.05)$ between control (2.37) and treatment with Trichoderma (4.13); (Table S3). Similar significant differences were observed for other parameters, Fm (Fp), Tfm and Area.

After treatment with $T$. asperellum IZR D-11, all investigated parameters of chlorophyll fluorescence increased, but the PI increased the most (by 75\%) in seedlings treated with Trichoderma compared to the control (Fig. 3). The area parameter above the fluorescence transient for the $T$. asperellum IZR D-11 treatment was also greater.

The water content measured in 42 leaves via wet and dry weight assessment, was significantly higher in oaks treated with $T$. asperellum IZR D-11 than in the control plants (Table S4).

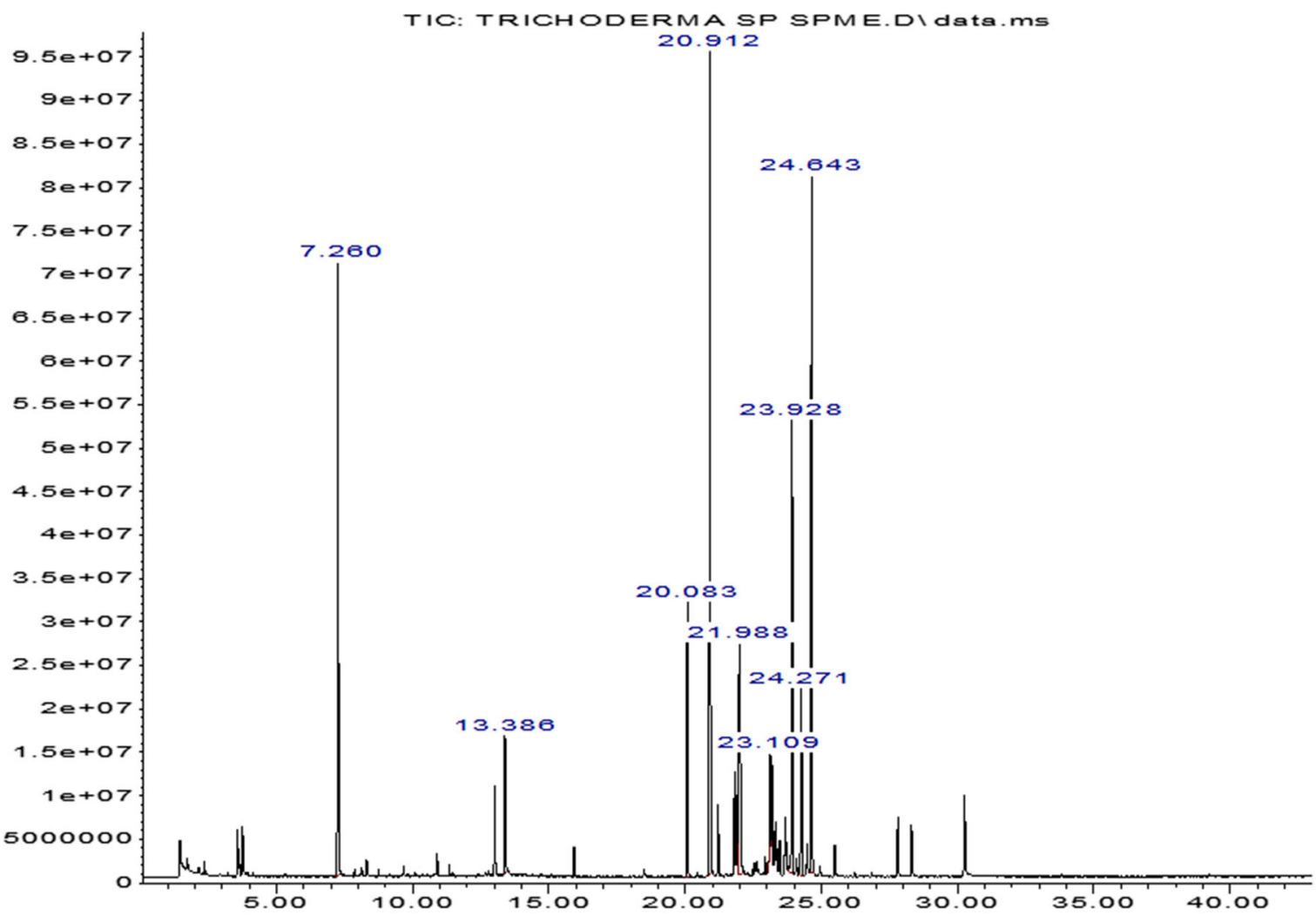

Time-->

Fig. 2 Chromatogram with HS-SPME/GC-MS analysis of VOCs emitted by Trichoderma asperellum. 
Fig. 3 A spider plot of the chlorophyll fluorescence parameters of oak leaves. Abbreviations: Fo - minimum chlorophyll fluorescence; Fm (Fp) - maximum chlorophyll fluorescence; Fv/fm - maximum quantum efficiency of photosystem II; Tfm - maximum time value of fluorescence (Fm); Area - the area above the chlorophyll fluorescence curve between Fo and Fm; PI - total performance index of chlorophyll fluorescence (also called productivity index).

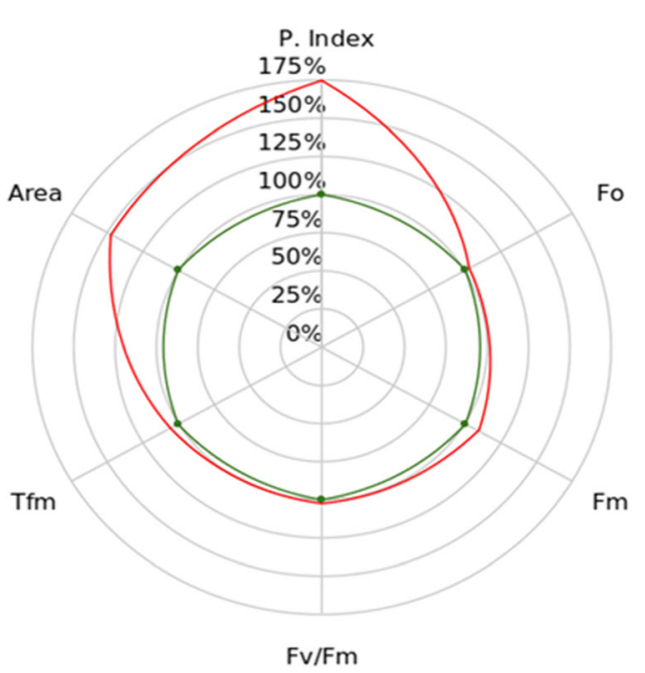

Control

- Trichoderma sp. D-11 spraying

\section{Discussion}

\section{Biological control efficacy}

The test results with efficacy over three years after application of the $T$. asperellum IZR D-11 as a BCA has not been previously reported in Poland or elsewhere as far as we know. In 2017 (after BCA treatment in 2016), disease rating in the control plants reached 3.22 out of 4 which was the highest disease scoring reflecting heavy infection of leaves caused by E. alphitoides, where no symptoms of powdery mildew occurred on the leaves of plants treated with $T$. asperellum. After three years, molecular tests (qPCR) revealed that in asymptomatic leaves, Trichoderma was not detected, but it was present in the rhizosphere soil of treated oak seedlings.

Increased total performance index (PI) reflects plant tolerance to adverse environmental conditions, meaning that plants can cope better with the stress. A lower area above the fluorescence curve between Fo and Fm in the control treatment indicated that the transfer of electrons from the reaction centers to the quinine pool is disrupted. Area reflects any changes in the shape of the induction kinetics between Fo and Fm, that is not evident on the basis of other parameters such as Fo, Fm, $\mathrm{Fv} / \mathrm{fm}$, which express only change amplitude extreme values $\mathrm{Fo}$ and $\mathrm{Fm}$. The $\mathrm{T}_{\mathrm{fm}}$ value increased by $6 \%$, which suggested that the plants needed the prolonged time to reach a full reduction state of the primary electron acceptors and the significant reduction of PSII performance. Generally, T. asperellum IZR D-11 treatment improved the photosynthetic efficiency compared to the control seedlings.
The antagonistic fungus $T$. asperellum positively influenced not only efficiency of oak seedlings photosynthesis but also increased the total water content in oak leaves. We supposed that BCA can serve as a preventive measure to reduce the energy losses in the process of water transpiration in infected plants. Water stress is one of important factors, which can dramatically change physiological condition of plants. Prosyannikova (2002) noted that infection of oaks $Q$. petraea by the pathogenic fungus E. alphitoides is accompanied by pathological changes in the water regime of plants. She also showed an increase of transpiration in diseased leaves. Enhanced water consumption in the process of transpiration is not fully compensated by absorption of water by roots, increases the water deficit in leaves of infected plants, and reduce their overall water content. Changes in cell metabolism of water $Q$. petraea, arising under the influence of the microspheres, lead to the inhibition of growth and, ultimately, can cause the death of the undergrowth part of plants. Our findings revealed that the use of antagonistic fungus positively affected the total content of water in oak leaves, and BCA can serve as a preventive measure to reduce energy losses in the process of water transpiration in infected plants.

\section{VOCs produced by Trichoderma}

It has been reported that the VOCs released by Trichoderma spp. play an important role in its antifungal activity (Vinodkumar et al. 2017; Sunpapao et al. 2018); they can induce systemic resistance (Yi et al. 2009) or promote plant growth (Vinale et al. 2006). The 
Trichoderma genus employs several modes of action contributing to biocontrol activity, and these modes vary much depending on the strain and environmental conditions. Some strains act directly against pathogens via mycoparasitism, competition, or antibiosis (Vinale et al. 2008; Monfil and Casas-Flores 2014; Vos et al. 2015); others promote plant growth (Aly and Manal 2009; Christopher et al. 2010; Yadav et al. 2011) or induce natural plant protection at the site of infection as well as at a distance from the pathogen, resulting in induced plant systemic resistance (López-Bucio et al. 2015; Vos et al. 2015; Zhang et al. 2016). We speculate that the curative effect (the lightly infected leaf blades went from a low level to even less disease) in 2016 on common pedunculate oak seedlings was achieved because of mycoparasitism and plant growth promotion, but the residual efficacy over the next three years might have been a consequence of the Trichoderma asperellum being able to establish in the plant or on the plant surface, and induce systemic resistance in subsequent seasons.

Furthermore some of the volatiles produced by T. asperellum are known to have antifungal activity and this might contribute to the decreased disease. To our knowledge, some of the volatile compounds identified were recorded for the first time in T. asperellum and they are inhibitory to powdery mildew fungi (ContrerasCornejo et al. 2016; Li et al. 2018; Guo et al. 2019). We found aliphatic carbonyls such as acetone, 3-octanone and acetoin, as well as esters, including ethyl tiglate, ethyl 3hydroxybutanoate and methyl 2-ethylhexanoate. Acetoin is a known activator of induced systemic resistance (ISR) (Rudrappa et al. 2010). Confirmation of this speculation can be done in future research to reveal the mechanism of Trichoderma secondary metabolites and their role in the disease biocontrol process. The volatile bioactive metabolites of Trichoderma such as 6-pentyl- $\alpha$-pyrone are known to exhibit multiple actions such as inhibiting growth of fungal mycelium, spore germination, and pigmentation of plant pathogenic fungi (Salwan et al. 2019). Also, Bhardwaj and Kumar (2017) reported that T. asperellum can produce many important VOCs that allow diverse functions ranging from anti-pathogenic to plant growth promotion. Our observations of Trichoderma in leaves where it had not been applied suggests that it can spread and establish. As well, the finding of Trichoderma in rhizosphere soil is consistent with induction of plant resistance perhaps mediated by VOCs. Defense responses elicited by Trichoderma in Arabidopsis are complex and involve the canonical defense hormones salicylic acid (SA) and jasmonic acid (JA), as well as phytoalexin camalexin, which may be important factors in boosting plant immunity. Co-cultivation of plant roots with these fungi also induces hydrogen peroxide accumulation which correlates with induction of pathogenesis-related reporter markers pPrla:uidA and pLox2:uidA (Contreras-Cornejo et al. 2011). Another strain of T. asperellum T34 conferred protection against Pseudomonas syringe through regulation of proteins involved in adaptation to stress, isoprenoid and ethylene biosynthesis, photorespiration and carbohydrate metabolism (Segarra et al. 2009; Yedidia et al. 1999).

Volatile organic compounds play an important role in the protection of plants against pests and pathogens. Volatiles produced by $T$. asperellum were tested against Fusarium oxysporum, Fusarium solani, Macrophomina phaseolina and Pythium ultimum (Boat et al. 2020). As a result, it was found that fungus produced volatile and non-volatile inhibitory metabolites as well as hydrolytic enzymes (chitinase, cellulase, protease and lipase). Li et al. (2018) found that T. asperellum, in contrast to $T$. virens or T. harzianum, did not secrete greater amount of volatiles in response to $F$. oxysporum infection. Moreover, Wonglom et al. 2019 demonstrated that VOC's of T. asperellum can mediate antifungal activity, defense response and promote growth of lettuce (Lactuca sativa).

In recent years, VOC's emitted by different strains of T. asperellum, such as: T1 (Wonglom et al. 2020), LF15 (Sim et al. 2019), LU1370 (Nieto-Jacobo et al. 2017) and IsmT5 (Kottb et al. 2015), have been analyzed. These investigations revealed the emission of 4 (Kottb et al. 2015) to maximum 22 compounds (Kottb et al. 2015; Wonglom et al. 2019), whereas we detected 49 volatiles emitted by T. asperellum IZR D-11. Our results confirmed results from previous studies showing the presence of aliphatic alcohols e.g. 2-methyl-1-butanol and 2-ethyl-1-hexanol in T. asperellum emissions (Sim et al. 2019; Wonglom et al. 2019), as well as sesquiterpenes and monoterpenes (Nieto-Jacobo et al. 2017; Sim et al. 2019; Wonglom et al. 2020), and aliphatic esters and carbonyls (Kottb et al. 2015). Moreover, in volatile emissions of $T$. asperellum, we identified compounds previously detected in other Trichoderma species but not previous reported for T. asperellum including sesquiterpenes such as $\beta$-farnesene found in $T$. atroviride (Stoppacher et al. 2010) and T. asperelloides (GalHemed et al. 2011), $\beta$-bisabolene found in T. atroviride (Stoppacher et al. 2010; Polizzi et al. 
2011) and T. asperelloides (Gal-Hemed et al. 2011), and $\beta$-elemene and germacrene $\mathrm{D}$ in T. virens (Nieto-Jacobo et al. 2017). It is quite likely that the compounds mentioned play crucial roles in the plant defense. For instance, Watanabe et al. (1990) found that sesquiterpenes of the daucane type exhibited antifungal activity against various yeast and dermatophytes, and effectively inhibit growth of Candida albicans.

Aforementioned compounds recorded in our strain of T. asperellum IZR D-11 have not been previously reported for other Trichoderma species (Siddiquee 2014), therefore future work should investigate the role of these compounds in plant disease resistance. Our results suggest that antagonistic microorganism $T$. asperellum IZR $\mathrm{D}-11$ has a potential as BCA in the control of oak powdery mildew in forest nurseries.

\section{Conclusions}

1) DNA sequencing of the Belarusian strain Trichoderma IZR D-11 identified it as Trichoderma asperellum which can act as a potential Biological Control Agent against Erysiphe alphitoides, the cause of oak powdery mildew.

2) The volatile secondary metabolites identified below were reported for the first time in T. asperellum and may play an important role in suppression of disease caused by E. alphitoides: sesquiterpenes daucene, dauca-4(11),8-diene isodaucene; aliphatic alcohols - 3-hepten-1-ol; aliphatic carbonyls - acetone, 3-octanone and acetoin, as well as esters, including: ethyl tiglate, ethyl 3-hydroxybutanoate and methyl 2-ethylhexanoate also phenylethyl alcohol, linalool and 1,2-dimethylsulfide.

3) The antagonistic fungus $T$. asperellum not only increased oak seedling photosynthesis but also increased the total water content of oak leaves, which can serve preventively to reduce energy losses during water transpiration in infected plants.

4) Applications of T. asperellum in the first year was able to suppress disease in the subsequent three years and hence is promising for longer-lasting control of oak powdery mildew particularly in nurseries.

Supplementary Information The online version contains supplementary material available at https://doi.org/10.1007/s10658020-02162-y.
Authors' contributions Conceptualization: Tomasz Oszako, Dmitry Voitka; Methodology: Tomasz Oszako, Dmitry Voitka, Marcin Stocki, Tadeusz Malewski, Justyna Anna Nowakowska; Formal analysis and investigation: Tomasz Oszako, Dmitry Voitka, Marcin Stocki, Natalia Stocka, Justyna Anna Nowakowska, Daria Berezovska, Tadeusz Malewski; Writing original draft preparation: Tomasz Oszako, Dmitry Voitka; Writing - review and editing: Tomasz Oszako, Dmitry Voitka, Marcin Stocki, Justyna Anna Nowakowska, Anna Linkiewicz, Tom Hsiang; Funding acquisition: Tomasz Oszako, Supervision: Tom Hsiang, Lassaâd Belbahri. All authors contributed to writing the manuscript.

Funding The research was supported by FRI Sękocin Stary, fellowship granted to Dmitry Voitka and Lassaâd Belbahri.Data availabilityNot relevant.

\section{Compliance with ethical standards}

Conflicts of interest The authors declare no conflict of interest.

Ethics approval There is no ethical issue in the present paper.

Research involving human participants and/or animals Not relevant.

Consent to participate All authors consent to participate.

Consent for publication All authors have read and agreed to the published version of the manuscript.

Code availability Not relevant.

Open Access This article is licensed under a Creative Commons Attribution 4.0 International License, which permits use, sharing, adaptation, distribution and reproduction in any medium or format, as long as you give appropriate credit to the original author(s) and the source, provide a link to the Creative Commons licence, and indicate if changes were made. The images or other third party material in this article are included in the article's Creative Commons licence, unless indicated otherwise in a credit line to the material. If material is not included in the article's Creative Commons licence and your intended use is not permitted by statutory regulation or exceeds the permitted use, you will need to obtain permission directly from the copyright holder. To view a copy of this licence, visit http://creativecommons.org/licenses/by/4.0/.

\section{References}

Altschul, S. F., Gish, W., Miller, W., Myers, E. W., \& Lipman, D. J. (1990). Basic Local Alignment Search Tool. Journal of Molecular Biology, 215, 403-410. 
Aly, M. H., \& Manal, Y. H. (2009). Vesicular-arbuscular mycorrhiza and Trichoderma virdi as deterrents against soil-borne root rot disease of sugar beet. Sugar Tech, 11(4), 387-391.

Belbahri, L., Chenari Bouket, A., Rekik, I., Alenezi, F. N., Vallat, A., Luptakova, L., Petrovova, E., Oszako, T., Cherrad, S., Vacher, S., \& Rateb, M. E. (2017). Comparative Genomics of Bacillus amyloliquefaciens Strains Reveals a Core Genome with Traits for Habitat Adaptation and a Secondary Metabolites Rich Accessory Genome. Frontiers in Microbiology, 8, 1438. https://doi.org/10.3389 /fmicb.2017.01438.

Ben, M. F., Daoud, A., Chenari, B. A., Thissera, B., Kadri, Y., Cherif-Silini, H., Eshelli, M., Alenezi, F. N., Vallat, A., Oszako, T., Kadri, A., Ros-García, J. M., Rateb, M. E., Gharsallah, N., \& Belbahri, L. (2018). Date Palm Trees Root-Derived Endophytes as Fungal Cell Factories for Diverse Bioactive Metabolites. International Journal of Molecular Sciences, 19, 1986.

Benitez, T., Rincon, A. M., Limon, M. C., \& Codon, A. C. (2004). Biocontrol mechanisms of Trichoderma strains. International Microbiology, 7(4), 249-260.

Bhardwaj, N. R., \& Kumar, J. (2017). Characterization of volatile secondary metabolites from Trichoderma asperellum. Journal of Applied and Natural Science, 9(2), 954-959.

Boat, M. A. B., Sameza, M. L., Iacomi, B., Tchameni, S. N., \& Boyom, F. F. (2020). Screening, identification and evaluation of Trichoderma spp. for biocontrol potential of common bean damping-off pathogens. Biocontrol Science and Technology, $30,228-242$. https://doi.org/10.1080 /09583157.2019.1700909.

Braun, U., \& Cook, R. T. A. (2012). Taxonomic manual of the Erysiphales (powdery mildews). Utrecht: CBS-KNAW Fungal Biodiversity Centre.

Carbone, I., \& Kohn, L. M. (1999). A method for designing primer set for speciation studies in filamentous ascomycetes. Mycologia, 91(3), 553-556.

Cheffi, M., Chenari Bouket, A., Alenezi, F. N., Luptakova, L., Belka, M., Vallat, A., Rateb, M. E., Tounsi, S., Triki, M. A., \& Belbahri, L. (2019). Olea europaea L. Root Endophyte Bacillus velezensis OEE1 Counteracts Oomycete and Fungal Harmful Pathogens and Harbours a Large Repertoire of Secreted and Volatile Metabolites and Beneficial Functional Genes. Microorganisms, 7, 314.

Christopher, D. J., Raj, T. S., Rani, S. U., \& Udhayakumar, R. (2010). Role of defense enzymes activity in tomato as induced by Trichoderma virens against Fusarium wilt caused by Fusarium oxysporum $\mathrm{f}$ sp. lycopersici. Journal of Biopesticides, 3(1), 158-162.

Contreras-Cornejo, H. A., Macías-Rodríguez, L., Beltrán-Peña, E., Herrera-Estrella, A., \& López-Bucio, J. (2011). Trichoderma-induced plant immunity likely involves both hormonal- and camalexin-dependent mechanisms in Arabidopsis thaliana and confers resistance against necrotrophic fungi Botrytis cinerea. Plant signaling \& behavior, 6(10), 1554-1563.

Contreras-Cornejo, H. A., Macias-Rodriguez, L., Del-Val, E., \& Larsen, J. (2016). Ecological functions of Trichoderma spp. and their secondary metabolites in the rhizosphere: interactions with plants. FEMS Microbiology Ecology, 92(4), fiw036.
Desprez-Loustau, M. L., Feau, N., Mougou-Hamdane, A., \& Dutech, C. (2011). Interspecific and intraspecific diversity in oak powdery mildews in Europe: coevolution history and adaptation to their hosts. Mycoscience, 52, 165-173.

Druzhinina, I. S., Kopchinsky, A. G., \& Kubicek, C. P. (2006). The first 100 Trichoderma species characterized by molecular data. Mycoscience, 47(2), 55-64.

Druzhinina, I., Seidl-Seiboth, V., Herrera-Estrella, A., Kenerley, C. M., Horwitz, B. A., Monte, E., Mukherjee, P. K., Zeilinger, S., Grigoriev, I. V., \& Kubicek, C. P. (2011). Trichoderma, the genomics of opportunistic success. Nature Reviews Microbiology, 9(10), 749-759.

Elad, Y. (2000). Biological control of foliar pathogens by means of Trichoderma harzianum and potential modes of action. Crop Protection, 19, 709-714.

Elad, Y., Kirshner, B., Yehuda, N., \& Sztejnberg, A. (1998). Management of powdery mildew and gray mold of cucumber by Trichoderma harzianum T39 and Ampelomyces quisqualis AQ10. BioControl, 43, 241-251.

Gal-Hemed, I., Atanasova, L., Komon-Zelazowska, M., Druzhinina, I. S., Viterbo, A., \& Yarden, O. (2011). Marine Isolates of Trichoderma spp. as Potential Halotolerant Agents of Biological Control for Arid-Zone Agriculture. Applied and Environmental Microbiology, 77(15), 5100-5109.

Guo, Y., Ghirardo, A., Weber, B., Schnitzler, J. P., Benz, J. P., \& Rosenkranz, M. (2019). Trichoderma Species Differ in Their Volatile Profiles and in Antagonism Toward Ectomycorrhiza Laccaria bicolor. Frontiers in Microbiology, 10, 891. https://doi.org/10.3389/fmicb.2019.00891.

Hermosa, M. R., Grondona, I., Iturriaga, E. A., Diaz-Minguez, J. M., Castro, C., Monte, E., \& Garcia-Acha, I. (2000). Molecular characterization and identification of biocontrol isolates of Trichoderma spp. Applied and Environmental Microbiology, 66(5), 1890-1898.

Hermosa, R., Viterbo, A., Chet, I., \& Monte, E. (2012). Plantbeneficial effects of Trichoderma and of its genes. Microbiology, 158(1), 17-25. https://doi.org/10.1099 /mic.0.052274-0.

Isidorov, V. A., Stocki, M., \& Vetchinikova, L. (2019). Inheritance of specific secondary volatile metabolites in buds of white birch Betula pendula and Betula pubescens hybrids. Trees, 33, 1329-1344.

Keča, N., Koufakis, I., Dietershagen, J., Nowakowska, J. A., \& Oszako, T. (2016). European oak decline phenomenon in relation to climatic changes. Folia Forestalia Polonica, 58(3), 170-177.

Khvasko, A. V. (2004). Особенности развития мучнистой росы дуба в условиях Беларуси и усовершенствование защитных мероприятий [Peculiarities of oak powdery mildew in the conditions of Belarus and improvement of protective measures: Thesis of Dissertation Candidate Agriculture Sciences. Minsk: BSTU.

Kottb, M., Gigolashvili, T., Großkinsky, D. K., \& Piechulla, B. (2015). Trichoderma volatiles effecting Arabidopsis: from inhibition to protection against phytopathogenic fungi. Frontiers in Microbiology, 6, 995. https://doi.org/10.3389 /fmicb.2015.00995.

Lee, S., Yap, M., Behringer, G., Hung, R., \& Bennett, J. W. (2016). Volatile organic compounds emitted by Trichoderma species mediate plant growth. Fungal Biol Biotechnol, 3(1), 1-14. 
Li, N., Alfiky, A., Wang, W., Islam, M., Nourollahi, K., Liu, X., \& Kang, S. (2018). Volatile Compound-Mediated Recognition and Inhibition Between Trichoderma Biocontrol Agents and Fusarium oxysporum. Frontiers in Microbiology, 9, 2614. https://doi.org/10.3389/fmicb.2018.02614.

Liu, Y. J., Sally, Whelen, S., \& Hall, B. D. (1999). Phylogenetic Relationships Among Ascomycetes: Evidence from an RNA Polymerase II Subunit. Molecular Biology and Evolution, 16(12), 1799-1808.

López-Bucio, J., Pelagio-Flores, R., \& Herrera-Estrella, A. (2015). Trichoderma as biostimulant: exploiting the multilevel properties of a plant beneficial fungus. Scientia Horticulturae, 196, 109-123. https://doi.org/10.1016/j.scienta.2015.08.043.

López, C. G., Muñoz Castellanos, L. N., Flores Ortiz, N. A., \& González González, J. A. (2019). Control of powdery mildew (Leveillula taurica) using Trichoderma asperellum and Metarhizium anisopliae in different pepper types. BioControl, 64, 77-89.

Marçais, B., \& Desprez-Loustau, M. (2014). European oak powdery mildew: impact on trees, effects of environmental factors, and potential effects of climate change. Annals of Forest Science, 71, 633-664. https://doi.org/10.1007/s13595-0120252-x.

Mazets, J. E. et al. (2012). Учебно-полевая практика по физиологии растений: практикум [Training and field practice in plant physiology: manual] Minsk/ BSPU.

Mbarga, J. B., Martijn Ten Hoopenb, G., Kuatéa, J., Adioboc, A., Ngonkeuad, M. E. L., Ambangd, Z., Akoad, A., Tondjea, P. R., \& Begoude, B. A. D. (2012). Trichoderma asperellum: A potential biocontrol agent for Pythium myriotylum, causal agent of cocoyam (Xanthosoma sagittifolium) root rot disease in Cameroon. Crop Protection, 36. https://doi.org/10.1016/j. cropro.2012.02.004.

Mefteh, F., Daoud, A., Chenari Bouket, A., Alenezi, F. N., Luptakova, L., Rateb, M. E., Kadri, A., Gharsallah, N., \& Belbahri, L. (2017). Fungal root microbiome from healthy and brittle leaf diseased date palm trees (Phoenix dactylifera L.) reveals a hidden untapped arsenal of antibacterial and broad spectrum antifungal secondary metabolites. Frontiers in Microbiology, 8, 307. https://doi.org/10.3389 /fmicb.2017.00307.

Monfil, V. O. \& Casas-Flores, S. (2014). Molecular mechanisms of biocontrol in Trichoderma spp. and their applications in agriculture. In: V. K. Gupta et al. (ed). Biotechnology and biology of Trichoderma, Chapter 32 - Molecular Mechanisms of Biocontrol in Trichoderma spp. and Their Applications in Agriculture, (pp.429-453), Elsevier, ISBN 9780444595768.

Mougou, A., Dutech, C., \& Desprez-Loustau, M.-L. (2008). New insights into the identity and origin of the causal agent of oak powdery mildew in Europe. Forest Pathology, 38(4), 275287. https://doi.org/10.1111/j.1439-0329.2008.00544.x.

Naznin, H. A., Kiyohara, D., Kimura, M., Miyazawa, M., Shimizu, M., \& Hyakumachi, M. (2014). Systemic Resistance Induced by Volatile Organic Compounds Emitted by Plant Growth-Promoting Fungi in Arabidopsis thaliana. PLoS ONE, 9(1), e86882.

Nieto-Jacobo, M. F., Steyaert, J. M., Salazar-Badillo, F. B., Nguyen, D. V., Rostás, M., Braithwaite, M., De Souza, J. T., Jimenez-Bremont, J. F., Ohkura, M., Stewart, A., \& Mendoza-Mendoza, A. (2017). Environmental Growth
Conditions of Trichoderma spp. Affects Indole Acetic Acid Derivatives, Volatile Organic Compounds, and Plant Growth Promotion. Frontiers in Plant Science, 8, 102. https://doi. org/10.3389/fpls.2017.00102.

Oszako, T., Żółciak, A., Tulik, M., Tkaczyk, M., Stocki, M., \& Nowakowska, J. A. (2019). Influence of Bacillus subtilis and Trichoderma asperellum on the development of birch seedlings infected with fine root pathogen Phytophthora plurivora. Sylwan, 163, 1006-1015.

Polizzi, V., Adams, A., Picco, A. M., Adriaens, E., Lenoir, J., Van Peteghem, C., De Saeger, S., \& De Kimpe, N. (2011). Influence of environmental conditions on production of volatiles by Trichoderma atroviride in relation with the sick building syndrome. Building and Environment, 46(4), 945954.

Prosyannikova, I. B. (2002). Influence of oak powdery dew on water exchange undergrowth Quercus petraea L. ex Liebl. (Fagaceae) [Влияние мучнистой росы дуба на водообмен подроста Quercus petraea L. ex Liebl. (Fagaceae)]. Ukrainian Botanical Journal, 59(5), 628-631.

Ratnasingham, S., \& Hebert, P. D. N. (2007). BOLD: The Barcode of Life Data System. Molecular Ecology Notes, 7, 355-364. https://doi.org/10.1111/j.1471-8286.2007.01678. $\mathrm{x}$.

Rudrappa, T. M., Biedrzycki, L., Kunjeti, S. G., Donofrio, N. M., Czymmek, K. J., Paré, P. W., \& Bais, H. P. (2010). The rhizobacterial elicitor acetoin induces systemic resistance in Arabidopsis thaliana. Journal Communicative \& Integrative Biology, 3(2), 130-138. https://doi.org/10.4161 /cib.3.2.10584.

Salwan, R., Rialch, N., \& Sharma, V. (2019). Bioactive Volatile Metabolites of Trichoderma: An overview. In H. Singh, C. Keswani, M. Reddy, E. Sansinenea, \& C. García-Estrada (Eds.), Secondary Metabolites of Plant Growth Promoting Rhizomicroorganisms. Singapore: Springer. https://doi. org/10.1007/978-981-13-5862-3-5.

Segarra, G., Van-der-Ent, S., Trillas, I., \& Pieterse, C. M. J. (2009). MYB72, a node of convergence in induced systemic resistance triggered by a fungal and a bacterial beneficial microbe. Plant Biology, 11, 90-96. https://doi.org/10.1111 /j.1438-8677.2008.00162.x.

Shin, T. S., Yu, N. H., Lee, J., Choi, G. J., Kim, J. C., \& Shin, C. S. (2017). Development of a Biofungicide Using a Mycoparasitic Fungus Simplicillium lamellicola BCP and Its Control Efficacy against Gray Mold Diseases of Tomato and Ginseng. The plant pathology journal, 33(3), 337-344. https://doi.org/10.5423/PPJ.FT.04.2017.0087.

Siddiquee, S. (2014). Recent advancements on the role and analysis of volatile compounds (VOCs) from Trichoderma. In V. K. Gupta, M. Schmoll, A. Herrera-Estrella, R. S. Upadhyay, I. Druzhinina, \& M. G. Tuohy (Eds.), Biotechnology and Biology of Trichoderma (pp. 139-175). Cambridge: Elsevier press. https://doi.org/10.1016/B978-0-444-59576-8.000114.

Sim, C. S. F., Yue, C. S., Cheow, Y. L., \& Ting, A. S. Y. (2019). Influence of metal stress on production of volatile inhibitory compounds by endophytes against Ganoderma boninense. Biocontrol Science and Technology, 29(9), 860-876. https://doi.org/10.1080/09583157.2019.1611735.

Stocki, M., Bakier, S., \& Isidorov, V. (2019). Study on extraction of biologically active compounds from birch (Betula) buds 
with supercritical carbon dioxide. Przemyst Chemiczny, 98, 1988-1991.

Stocki, M., Zapora, E., Rój, E., \& Bakier, S. (2018). Recovering biologically active compounds from logging residue of birch (Betula spp.) with supercritical carbon dioxide. Przemyst Chemiczny, 97, 774-778.

Stoppacher, N., Kluger, B., Zeilinger, S., Krska, R., \& Schuhmacher, R. (2010). Identification and profiling of volatile metabolites of the biocontrol fungus Trichoderma atroviride by HS-SPME-GC-MS. Journal of Microbiological Methods, 81, 187-193.

Sunpapao, A., Chairin, T., \& Ito, S. (2018). The biocontrol by Streptomyces and Trichoderma of leaf spot disease caused by Curvularia oryzae in oil palm seedlings. Biological Control, 123. https://doi.org/10.1016/j.biocontrol.2018.04.017.

Thissera, B., Alhadrami, H. A., Hassan, M. H. A., Hassan, H. M., Behery, F. A., Bawazeer, M., Yaseen, M., Belbahri, L., \& Rateb, M. E. (2020). Induction of Cryptic Antifungal Pulicatin Derivatives from Pantoea Agglomerans by Microbial Co-Culture. Biomolecules, 10, 268.

Topalidou, E. T., \& Shaw, M. W. (2016). Relationships between Oak powdery mildew incidence and severity and commensal fungi. Forest Pathology, 46(2), 104-115.

Tronsmo, A., \& Dennis, C. (1977). The use of Trichoderma species to control straw-berry fruit rots. Netherlands Journal of Plant Pathology, 83(1), 449-455.

Vinale, F., Marra, R., Scala, F., Ghisalberti, E. L., Lorito, M., \& Sivasithamparam, K. (2006). Major secondary metabolites produced by two commercial Trichoderma strains active against different phytopathogens. Letters in Applied Microbiology, 43, 143-148.

Vinale, F., Sivasithamparam, K., Ghisalberti, E. L., Marra, R., Woo, S. L., \& Lorito, M. (2008). Trichoderma-plant-pathogen interactions. Soil Biology and Biochemistry, 40, 1-10.

Vinodkumar, S., Indumathi, T. \& Sevugapperumal, N. (2017). Trichoderma asperellum (NVTA2) as a potential antagonist for the management of stem rot in carnation under protected cultivation. Biological Control, 113, https://doi.org/10.1016 j.biocontrol.2017.07.001

Vos, C. M. F., De Cremer, K., Cammue, B. P. A., \& De Coninck, B. (2015). The toolbox of Trichoderma spp. in the biocontrol of Botrytis cinerea disease. Molecular Plant Pathology, 16(4), 400-412. https://doi.org/10.1111/mpp.12189.
Watanabe, N., Yamagishi, M., Mizutani, T., Kondoh, H., Omura, S., Hanada, K., \& Kushida, K. (1990). CAF-603: a new antifungal carotane sesquiterpene. Isolation and structure elucidation. Journal of Natural Products, 53, 1176-1181.

White, T. J., Bruns, T. D., Lee, S., \& Taylor, J. (1990). Amplification and direct sequencing of fungal ribosomal RNA genes for phylogenetics. In M. A. Innis, D. H. Gelfand, J. J. Sninsky, \& T. J. White (Eds.), PCR protocols. A guide to methods and applications (pp. 315-322). San Diego: Academic Press.

Wonglom, P., Daengsuwan, W., Ito, S., \& Sunpapao, A. (2019). Biological control of Sclerotium fruit rot of snake fruit and stem rot of lettuce by Trichoderma sp. T76-12/2 and the mechanisms involved. Physiological and Molecular Plant Pathology, 107. https://doi.org/10.1016/j. pmpp.2019.04.007.

Wonglom, P., Ito, S., \& Sunpapao, A. (2020). Volatile organic compounds emitted from endophytic fungus Trichoderma asperellum $\mathrm{T} 1$ mediate antifungal activity, defense response and promote plant growth in lettuce (Lactuca sativa). Fungal Ecology, 43, 100,867. https://doi.org/10.1016/j. funeco.2019.100867.

Yadav, J., Verma, J. P., \& Tiwari, K. N. (2011). Plant growth promoting activities of fungi and their effect on chickpea plant growth. Asian Journal of Biological Sciences, 4(3), 291-299.

Ye, J., Coulouris, G., Zaretskaya, I., Cutcutache, I., Rozen, S., \& Madden, T. (2012). Primer-BLAST: A tool to design targetspecific primers for polymerase chain reaction. $B M C$ Bioinformatics, 13, 134.

Yedidia, I., Benhamou, N., \& Chet, I. (1999). Induction of defense responses in cucumber plants (Cucumis sativus L.) by the biocontrol agent Trichoderma harzianum. Applied and Environmental Microbiology, 65, 1061-1070.

Yi, M., Nwe, K. T., Vanavichit, A., Chai-arree, W., \& Toojinda, T. (2009). Marker assisted backcross breeding to improve cooking quality traits in Myanmar rice cultivar Manawthukha. Field Crops Research, 113(2), 178-186.

Zhang, F., Ge, H., Zhang, F., Guo, N., Wang, Y., Chen, L., Ji, X., \& Li, C. (2016). Biocontrol potential of Trichoderma harzianum isolate T-aloe against Sclerotinia sclerotiorum in soybean. Plant Physiology and Biochemistry, 100, 64-74. 